\title{
Actinic lichen planus
}

INSERM

\section{Source}

INSERM. (1999). Orphanet: an online rare disease and orphan drug data base. Actinic lichen planus. ORPHA:254395

Actinic lichen planus (LP) is a rare variant of cutaneous lichen planus (see this term) characterized by the development of photo-distributed lichenoid lesions. 